
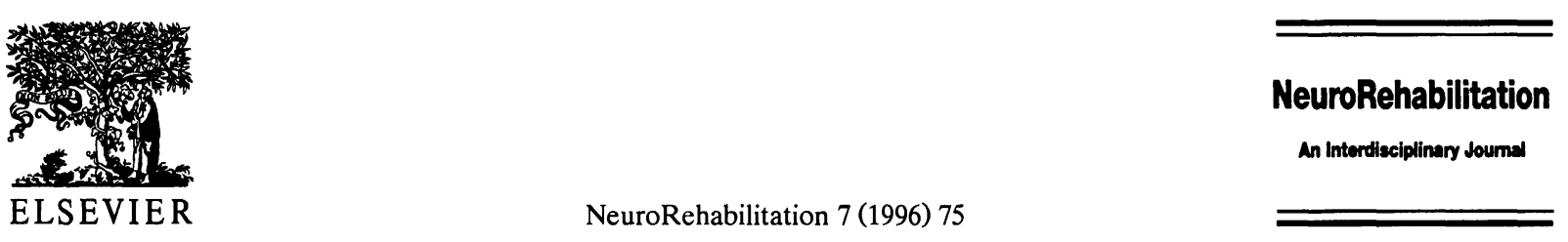

\title{
Upcoming conferences
}

International Conference on Recent Advances in Neuro Traumatology

September 8-11, 1996

Rimini-Riccione, Italy

Further information from:

New Team,

Zia Ghiritti 2,

J-43100, Parma, Italy

Tel: 395212 93913; Fax: 39521294036.
Congress of NeuroRehabilitation

October 17-19, 1996

Rheinfelden / Switzerland

International symposium under the patronage of the Swiss Neurological Society.

Further information from:

Congress Secretariat, Rehaklinik Rheinfelden Salinenstr. 98

CH-4310 Rheinfelden

Tel: 00416183652 35; Fax: 0041618365353. 